TRABAJOS DE PREHISTORIA

67, N. ${ }^{\circ} 1$, enero-junio 2010, pp. 227-243, ISSN: 0082-5638

doi: $10.3989 /$ tp. 2010.10038

\title{
Hacia el Lejano Oeste. Arte levantino en el acceso a la Meseta: la Roca Benedí (Jaraba, Zaragoza) (1)
}

\author{
To the Far West. Levantine Rock Art in the access to the Meseta: Roca Benedi \\ (Jaraba, Zaragoza)
}

Pilar Utrilla $(*)$

Manuel Bea $(*)$

Serafín Benedí $(* *)$

\begin{abstract}
RESUMEN
Se da a conocer el hallazgo de cinco motivos, cuatro de ellos del más clásico estilo levantino y de color negro, en una zona inédita: el valle del río Mesa en la cuenca del río Jalón, camino natural de acceso a la Meseta Sur. La roca pintada se ubica además en territorio de aguas termales, muy próximo a los balnearios de Jaraba, destacándose como el yacimiento levantino más occidental conocido en Aragón. Su patrón estilístico encaja en los tipos de arqueros que se desplazan, con paralelos temáticos en el grupo Bajo Aragón/Maestrazgo/Bajo Ebro. Su ubicación en un cañón sinuoso reproduce el esquema de la zona de Valltorta (Castellón) y subraya su carácter de marcador territorial, situándose en un anfiteatro natural tras un meandro en la confluencia con un barranco perpendicular y en la zona más visible de todo el barranco.
\end{abstract}

\begin{abstract}
We focus on the discovery of four black figures, of the most classic Levantine rock art style, in a previously unknown area: the river Mesa valley in the Jalon basin, that is the natural acces route to the South Meseta, in the Iberian System. The painted rock is located in a territory with thermal sources, very close to the spa resort of Jaraba. Its stylistic pattern corresponds with the Levantine "flying motion" archers, with thematical parallels in the group of the Bajo Aragón/Maestrazgo/Bajo Ebro, and it represents the westernmost Levantine rock
\end{abstract}

(*) Área de Prehistoria. Departamento de Ciencias de la Antigüedad. Universidad de Zaragoza. c/ Pedro Cerbuna 12. 50009 Zaragoza. Correos electrónicos: utrilla@unizar.es; manumbea@unizar.es

(**) c/ Romea 8 (1. ${ }^{\circ}$ D). 50002 Zaragoza. Correo electrónico: serafinbenedi@hotmail.com

Recibido: 20-XII-2009; aceptado: 1-III-2010. art site in Aragón. Its location in a winding ravine reproduces the Valltorta scheme, and emphasises its character as a territorial marker, being a natural amphitheatre at the junction of two ravines, in the most visible zone of the hole route.

Palabras clave: Arte levantino; Península Ibérica; Movilidad territorial; Aguas termales; Mesolítico; Neolítico; Calcos digitales.

Key words: Levantine Rock Art; Iberian System; Territory Mobility; Thermal water; Mesolithic, Neolithic, Digital traces.

\section{INTRODUCCIÓN}

La zona del barranco de la Cañada del Campi1lo, a cuya entrada se localiza la Ermita de Nuestra Señora de Jaraba, presenta unas condiciones excelentes para contener vestigios de ocupación por parte de sociedades prehistóricas. Es un lugar protegido y soleado, ubicado a sólo $2 \mathrm{~km}$ de las cálidas aguas termales que manan de rocas del Cretácico Superior con una potencia de 10 a 15 MW y que son explotadas en los actuales balnearios. Pertenece a la misma red hidrogeológica que transcurre bajo el río Henar en su confluencia con el Jalón y que aflora en los manantiales de Alhama de Aragón, Embid de Ariza y Deza.

(1) Este estudio se inserta en el proyecto DGES HAR2008-05451/HIST La movilidad en el Valle Medio del Ebro: del Paleolítico Superior al Neolítico y en el Grupo de Investigación Primeros Pobladores del Valle del Ebro (H-07) del Gobierno de Aragón. 
Dan testimonio de las favorables condiciones de habitabilidad el rosario de asentamientos paleolíticos (2) que jalonan este acceso a la alta y fría meseta soriana. Allí se establecieron durante los distintos períodos del gélido Dryas los habitantes Magdalenienses de los abrigos Vergara y Alexandre en Deza (Utrilla et al. 1999; Utrilla y Blasco 2000) o de la Peña del Diablo 1 y 2 en Cetina (Utrilla y Domingo 2003), o los posibles mesolíticos que dejaron un microburil en el abrigo de Artal-Domingo junto al congosto de Embid de Ariza. En julio de 1995 P. Utrilla obtuvo del Gobierno de Aragón y de la Junta de Castilla y León permiso de prospección para toda la zona "termal" comprendida entre Deza y Jaraba, revisando las cuevas y abrigos localizados en el curso del río Henar entre Deza y Cetina, así como del río Mesa y sus afluentes en Jaraba.

Los resultados fueron muy positivos en la primera zona, la más intensamente prospectada, pero fallidos en la segunda ya que los espléndidos abrigos unas veces estaban ocupados por balnearios (los de Serón y la Virgen), otras por ermitas rupestres (Nuestra Señora de Jaraba) y, las más, por corrales cerrados y en uso.

En suma, el cañón tenía un alto valor estratégico para pueblos cazadores que obtendrían allí fácilmente el éxito en la caza: sus altas paredes verticales (Lám. I.1), su trazado sinuoso tipo Valltorta (Lám. I.2), sus quiebros bruscos en el trazado, los abundantes apostaderos de ojeo, sus abrigos habitables, la posibilidad, en fin, de dar caza en sus $10 \mathrm{~km}$ de desarrollo a ungulados, o incluso de proceder a una especie de semiestabulación, tal como propuso Davidson (1989) para ciervos en el valenciano valle de la Marchuquera o para renos en la Gorge d'Enfer, todo lo cual lo convertían en un lugar con un significado especial para los grupos prehistóricos.

El Santuario rupestre de Nuestra Señora de Jaraba, a $2 \mathrm{~km}$ de distancia del balneario termal de la Virgen, marcaría sin duda la entrada (o la salida) al cañón y “cristianizaría” el tortuoso y singu-

(2) Este poblamiento es bien conocido a lo largo de todo el Paleolítico en zonas de la cuenca del Jalón famosas por sus aguas termales, ya sea en el Paleolítico Inferior (Torralba y Ambrona, próximos a Fuencaliente de Medinaceli; bifaces de Fuentes de Jiloca, Miedes y Montón junto al balneario de Paracuellos de Jiloca); en el Medio (Paridera de la Condesa junto a la surgencia de los Ojos de Pontil en Rueda de Jalón); y en el Superior (los citados yacimientos magdalenienses de Deza y Cetina en el Henar, o la Tosuguera en Benamira en el alto Jalón). lar barranco, constituyendo el abrigo de la ermita un punto ideal para establecer un lugar de hábitat o para contener pinturas prehistóricas que marcaran la "posesión" del cañón para los creadores, si se acepta a priori la conocida hipótesis de Llavori de Micheo (1988-1989).

En suma, la espectacularidad del paisaje, unida a la existencia de aguas termales en las cercanías, convierten a este territorio de la Cordillera Ibérica en una de las zonas con mayor potencialidad en cuanto a la ocupación prehistórica se refiere, tanto desde el punto de vista de yacimientos de habitación como de estaciones con arte rupestre.

Pasaron catorce años desde nuestra primera prospección pero fue un vecino de la localidad de Jaraba, D. Serafín Benedí, muy preocupado por la actividad cultural de la zona, quien el 7 de septiembre de 2009 se puso en contacto con P. Utrilla para comunicarle el hallazgo de posibles pinturas rupestres en el barranco descrito. El 11 de septiembre, acompañados por M. Bea, confirmamos su pertenencia al arte rupestre levantino, informando de inmediato al Departamento de Cultura del Gobierno de Aragón para proceder a su protección. Con fecha 24 de septiembre se obtuvo el permiso de calco y estudio, así como de prospección de los $10 \mathrm{~km}$ lineales que constituyen toda la cañada del Campillo, con la intención de documentar si existían más pinturas en el resto del cañón. El resultado, por el momento, ha sido negativo (3), aunque resta por prospectar un tercio del recorrido.

\section{LOCALIZACIÓN Y ENTORNO GEOGRÁFICO}

El nombre local del cañón oscila entre barranco de L'Auceca (contracción de la Hoz Seca) o de la Ermita de la Virgen, en alusión al santuario rupestre. Sin embargo, en la cartografía del IGN (Hojas 436 Jaraba y 463 Milmarcos) es conocido como "Cañada de Campillo", en alusión a la localidad hacia la que parece dirigirse, siendo atravesado por la GR-24.

El acceso al conjunto rupestre se realiza siguiendo la carretera que atraviesa la población de

(3) No obstante, se han encontrado cuatro núcleos con grabados de época incierta, probablemente históricos. 

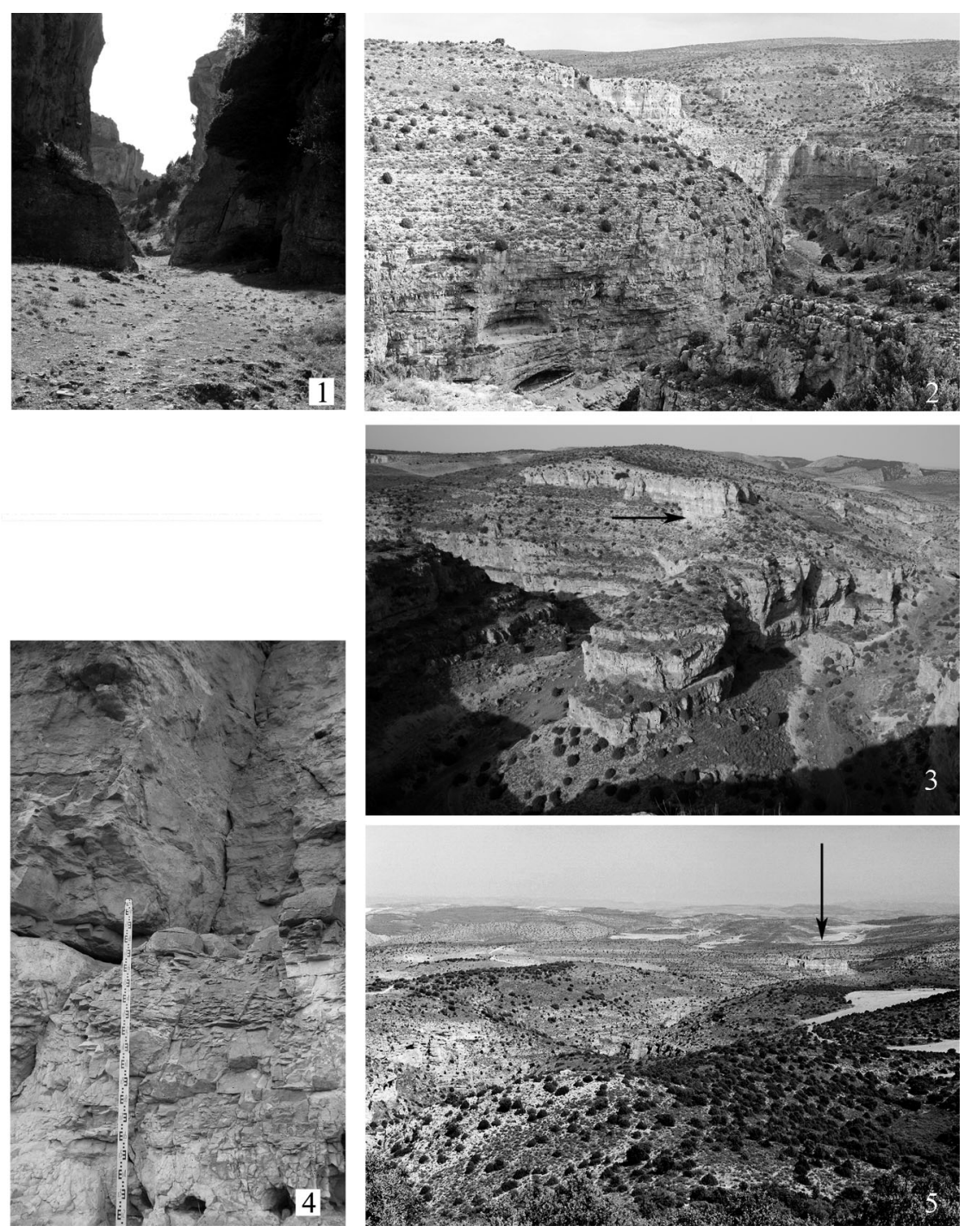

Lám. I. Contexto geográfico de Roca Benedí (Jaraba, Zaragoza). Las flechas indican la ubicación del farallón rocoso en el que se localizan las pinturas.

Jaraba en dirección a Calmarza (Lám. II). A mitad de camino, entre los puntos kilométricos 2 y 3 remontando el río Mesa, se abre a mano izquierda el citado cañón que lleva al Santuario de Nuestra Señora de Jaraba. Éste discurre de forma tortuosa a lo largo de unos $10 \mathrm{~km}$, recordando el conocido barranco de la Valltorta (Castellón) en el que se localizan los famosos abrigos con arte levantino. El acceso se realiza en su mayor parte llaneando por el fondo del barranco, en un recorrido espectacular que transcurre entre altos paredones de caliza en los que se abren numerosos abrigos, algunos de grandes dimensiones. Sin embargo, las pinturas no se localizan en ninguno de los mu- chos que existen en el entorno sino en un pequeño y anodino entrante rocoso en la zona baja de un farallón que se extiende del Noreste al Suroeste. Por tanto, tenemos que pensar que el lugar fue elegido cuidadosamente por su posición ya que, de otro modo, no se explica que se desecharan todos los abrigos y hornacinas que jalonan el recorrido.

Debemos tener siempre presente la posibilidad de que existieran más estaciones decoradas y que, por cuestiones de conservación, no se hayan preservado. En este sentido debemos destacar la altitud media del territorio en el que se localiza Roca Benedí, cercana a los 1.000 m s.n.m., con tempe- 


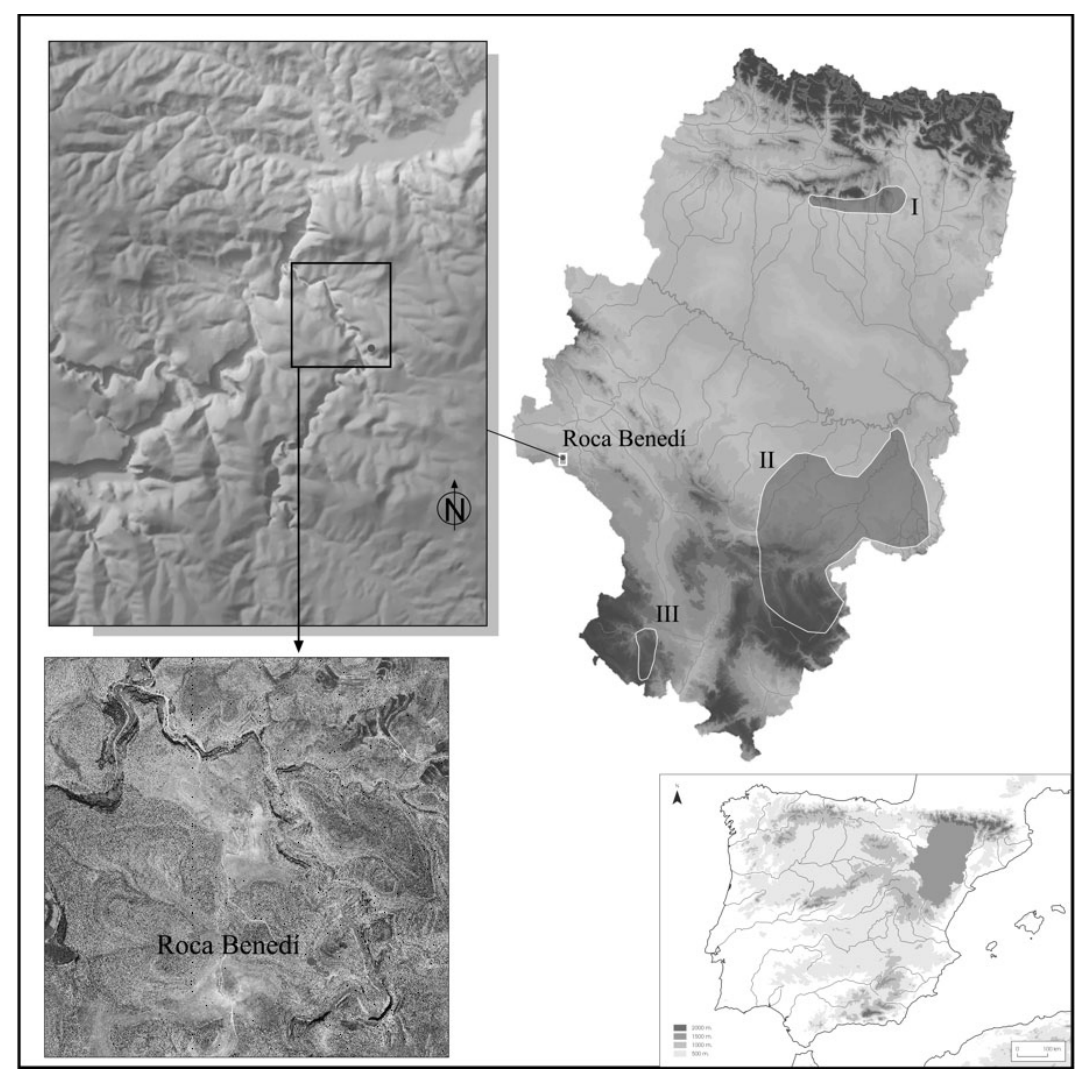

Lám. II. Localización de Roca Benedí (Jaraba, Zaragoza) en relación con los grupos pictóricos levantinos de Aragón: I. Alto Aragón; II. Bajo Aragón/Maestrazgo; III. Albarracín.

raturas medias muy bajas en invierno que determinan el alto grado de descamación de la roca.

A unos $2 \mathrm{~km}$ de la salida, es decir, de la confluencia del cañón en el río Mesa, se debe iniciar el ascenso por la ladera Oeste del barranco, cerca de la cueva denominada "de la Tienda", ascenso que no resulta demasiado complicado si se sigue una estrecha senda abierta por el ganado. Bastará con ir ganando altura hasta alcanzar la cota de los $860 \mathrm{~m}$ aproximadamente. Allí se obtiene un dominio absoluto sobre el terreno circundante, divisando desde las pinturas el gran meandro, de casi $300^{\circ}$, que describe el barranco en este punto (Lám. I.3).

Delante de las pinturas se extiende un espolón en el que se aprecia una posible construcción en piedra de morfología circular hoy totalmente derruida. Frente a ella, en la vertiente Este del barranco, se abre la cueva de las Grajas, una impresionante oquedad formada por el empuje de las aguas, lo que le confiere una especial sonoridad al funcionar como caja de resonancia que produ- ce un eco muy particular. En lo alto de la ladera derecha del barranco, frente al conjunto levantino, se documenta un asentamiento prehistórico donde la prospección de M. Bea y R. Domingo localizó cerámicas decoradas con cordones de uñadas.

La ubicación de las pinturas en este punto no resulta baladí, y sin duda ha de ponerse en relación con la significación del arte rupestre como marcador territorial. La estación decorada se ubica en el imponente meandro en el que se estrangula el curso del barranco, como sucede en el Barranc de la Valltorta que registra una especial concentración de abrigos pintados en la cara sur de los dos meandros más cerrados de su recorrido. A ello se suma la excelente acústica del anfiteatro natural en el que se ubican las pinturas, tal como se documenta en El Barranco Hondo (Martínez Bea 2004: 98-99) o en la Vacada (Martínez Bea 2006, 2009), ambos en Castellote, o en diversos conjuntos del grupo de la Valltorta, como el de La Saltadora (Villaverde y Martínez Valle 
2002: 200; Domingo et al. 2007). De igual modo debe comentarse que, al descender el barranco en dirección al Mesa, la roca donde se ubican las pinturas es visible desde varios kilómetros de distancia (Lám. I.5), algo similar a lo documentado por J.F. Ruiz (2005: 238) en la Peña del Escrito II de Villar del Humo, una roca visible desde más de $8 \mathrm{~km}$ de distancia.

Por otra parte, hay que señalar que es intenso el poblamiento prehistórico en la cuenca del río Jalón aunque aquí nos interesa sólo la época a la que suele atribuirse el arte levantino, bien al Mesolítico Geométrico, bien al Neolítico Antiguo o al Neolítico Final/Eneolítico (4). Así, destaca el potente foco del Neolítico Antiguo del Valle del Ambrona, con los yacimientos de Revilla y La Lámpara (Kunst y Rojo 1999) o el Campaniforme del mismo valle (Rojo et al. 2004) o el de la clásica Cueva de la Mora de Somaén (Barandiarán 1975). En cuanto al Mesolítico se documentan sólo algunos hallazgos aislados que denotan la presencia de estas gentes en la zona: como el microburil del citado abrigo de Artal-Domingo en Embid de Ariza (Utrilla y Domingo 2003) o algunos trapecios abruptos o microburiles de Vardalgal, en Morata de Jalón o del Parrizal, en Santa Cruz de Grío (Utrilla y Gimeno 1981).

Más próximos a las pinturas de Jaraba resultan algunos hallazgos de superficie de la cuenca media del río Mesa recogidos por J.L. Cebolla (5).

(4) No hemos querido desarrollar, por no ser el objetivo principal de este trabajo, cuestiones relativas a la adscripción cronológica y cultural de las pinturas. Plantear esta problemática, que ya hemos abordado en trabajos anteriores (Utrilla y Calvo 1999; Utrilla 2005; Utrilla y Martínez Bea 2006 y 2007) habría alargado considerablemente el artículo para, al final, no poder llegar a ninguna conclusión cerrada ya que la situación actual del debate cuenta con posicionamientos abiertos muy dispares. Basten citar los estudios de Alonso y Grimal (1994), Domingo (2006), Escoriza (2002), Fortea (1974), Fortea y Aura (1987), García Robles et al. (2005), Hernández et al. (1982), Hernández y Martí (2001), Hernández y Segura (2002), Hernández (2005), Martí y Hernández (1988), Mateo Saura (2002), Molina et al. (2003), Vicent (1990), Villaverde (2005), Villaverde y Martínez Valle (2002), Villaverde et al. (2006), incluso algunos trabajos que apuntan a la adscripción de determinados conjuntos rupestres levantinos de Albarracín como propios de momentos prehistóricos muy recientes (Martínez Bea 2006, 2008), por citar sólo algunos ejemplos.

(5) Así en la localidad de Labros, ubicada junto al inicio del barranco de la Ermita se halló un microburil (La Lastra), tres segmentos (Hornillos, La Lastra) y un triángulo de doble bisel (Fuente Mochel). Otro microburil apareció en Amayas (Laguna Seca) junto a un segmento abrupto, a lo que hay que añadir un taladro de larga punta de clara tipología neolítica procedente de Villel de Mesa (Cañamañas). En los mismos términos documenta Cebolla algunos asentamientos con cerámica campaniforme,

\section{DESCRIPCIÓN DE LOS MOTIVOS}

El conjunto pintado, compuesto por dos ciervos que miran hacia la izquierda, dos figuras humanas que lo hacen a la derecha y unos trazos lineales, se sitúa en una simple roca formada por dos lienzos en ángulo, aunque las pinturas sólo están ubicadas en el panel izquierdo. En el citado ángulo se abre una grieta hacia la que se dirigen las dos figuras humanas, tocándola las flechas del arquero que parecen estar introduciéndose ya en la misma.

La repisa que sirvió de base a los pintores, un lugar que hoy resulta muy incómodo, mide $5 \mathrm{~m}$ de longitud $\times 1,03 \mathrm{~m}$ de anchura y se encuentra a $2,85 \mathrm{~m}$ del suelo y a $3,5 \mathrm{~m}$ de altura del techo o visera que protege las pinturas. El panel decorado ocupa una superficie de 1,08 $\mathrm{m}$ de longitud por 0,71 de anchura, comenzando las pinturas a sólo $58 \mathrm{~cm}$ del suelo de la repisa (Lám. III).

\section{Motivo 1. Arquero}

Personaje masculino marchando a la derecha que porta arco sin cuerda y flechas en su mano izquierda (Lám. IV.2). Éstas parecen de ápice simple y emplumadura lanceolada, la representación habitual del arte levantino. Presenta peinado piriforme, de media melena vuelta hacia adentro y un espectacular tocado de forma triangular con un penacho de seis plumas. La articulación de la cabeza y el torso enmascara el diseño del cuello en la parte derecha, el cual queda casi oculto por la melena. El cuerpo aparece bien proporcionado con un tórax de tendencia triangular en visión frontal, perspectiva que pasa a lateral en las piernas, en especial en las bien modeladas pantorrillas, con una muy cuidada representación de los pies. A la altura de la rodilla se observan cintas que parecen ajustar bien un posible pantalón bombacho, bien unas polainas, sin descartar que se trate de un mero elemento decorativo y que el arquero fuera desnudo, estando representado el sexo por un trazo central muy perdido. En este caso ofrecería unos muslos demasiado gruesos y mal modelados, lo que no concuerda con la buena representación de las pantorrillas. En la zona de las caderas aparece un modelado apenas

en Hinojosa, Labros, Amayas, Milmarcos, Mochales, Villel de Mesa y Algar de Mesa. Estos yacimientos aparecen recogidos en Cebolla, J.L. 1986: El poblamiento prehistórico del sector medio del río Mesa (Guadalajara, Soria, Zaragoza). Tesis de Licenciatura inédita. Universidad de Zaragoza. Zaragoza. 


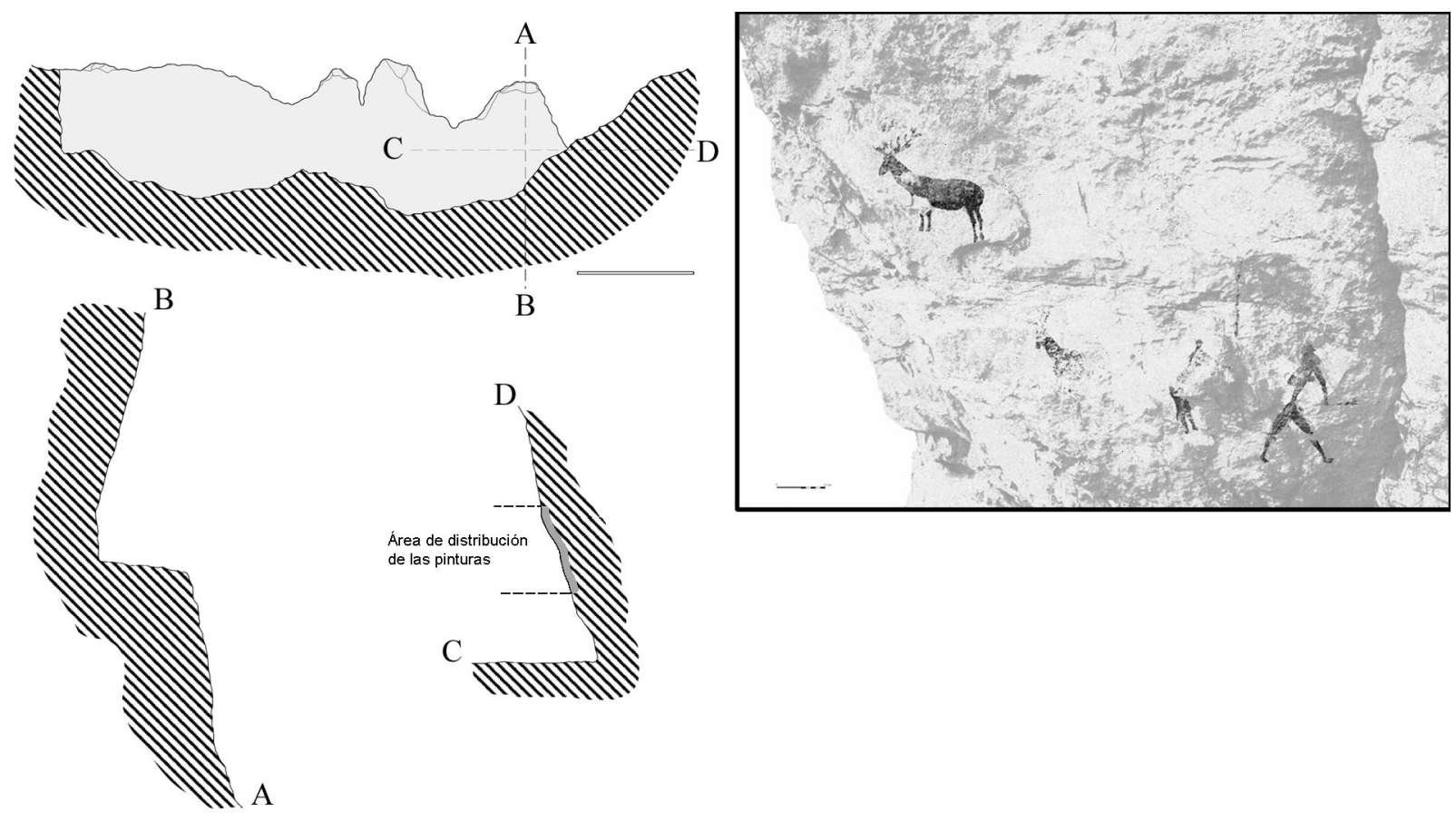

Lám. III. Planta y alzados de la estación rupestre. A la derecha: esquema del panel decorado con distribución de los motivos pictóricos, ver Lám. IV.

perceptible pero que consigue marcar la transición a los muslos.

El brazo derecho, en visión lateral correcta, aparece doblado en una postura típica del arte levantino, mientras en su izquierdo, de nuevo en visión frontal, se atisba por encima del codo un engrosamiento que podría corresponder a un brazalete.

Dimensiones del motivo 1: $30 \mathrm{~cm}$ de longitud máxima desde la cabeza al pie izquierdo y 18,7 $\mathrm{cm}$ de longitud máxima del arco. Su muslo derecho mide $2,8 \mathrm{~cm}$ de anchura máxima, mientras que el izquierdo alcanza los $2,3 \mathrm{~cm}$.

\section{Motivo 2. Mujer con niño}

A $11 \mathrm{~cm}$ a la izquierda del motivo 1, aparece una figura femenina en negro mirando a la derecha e inclinada hacia delante (Lám. IV.1). Muy mal conservada, parece llevar falda de picos hasta la pantorrilla o bien pantalones anchos que dan paso a unas pantorrillas gruesas y a unos pies anchos. Esta parte inferior del cuerpo ha sido representada en una perspectiva frontal, lo que contrasta con la lateral que se ha utilizado para el arquero. La parte correspondiente al tronco y cabeza apenas es vi- sible pero la zona conservada permite apreciar la inclinación de la espalda y la existencia, en perspectiva lateral, de un tronco grueso en tórax y abdomen, grosor que no es habitual en representaciones femeninas de este estilo.

En la parte superior del motivo aparece la figura de un niño, quizás tocado con un gorrito, que cabalga a la espalda de la mujer, irreconocible como tal por la ausencia de pintura conservada en la zona de los pechos.

La figura completa mide $22,7 \mathrm{~cm}$ de longitud máxima, desde la cabeza del supuesto niño hasta el pie izquierdo de la madre, alcanzando los 13,5 $\mathrm{cm}$ desde el glúteo hasta el pie izquierdo.

\section{Motivo 3. Trazos lineales}

La mujer del motivo n. $^{\circ} 2$ podría estar vinculada a un largo trazo vertical, de $20,5 \mathrm{~cm}$ de longitud, precedido de uno horizontal más corto de $3 \mathrm{~cm}$, que pudo estar unido a sus brazos. Un tercer trazo lineal de tendencia horizontal se localiza a la derecha del extremo final del trazo vertical, alcanzando los 5,4 cm (Lám. IV.1). La unión de estos dos últimos trazos no es visible por los des- 

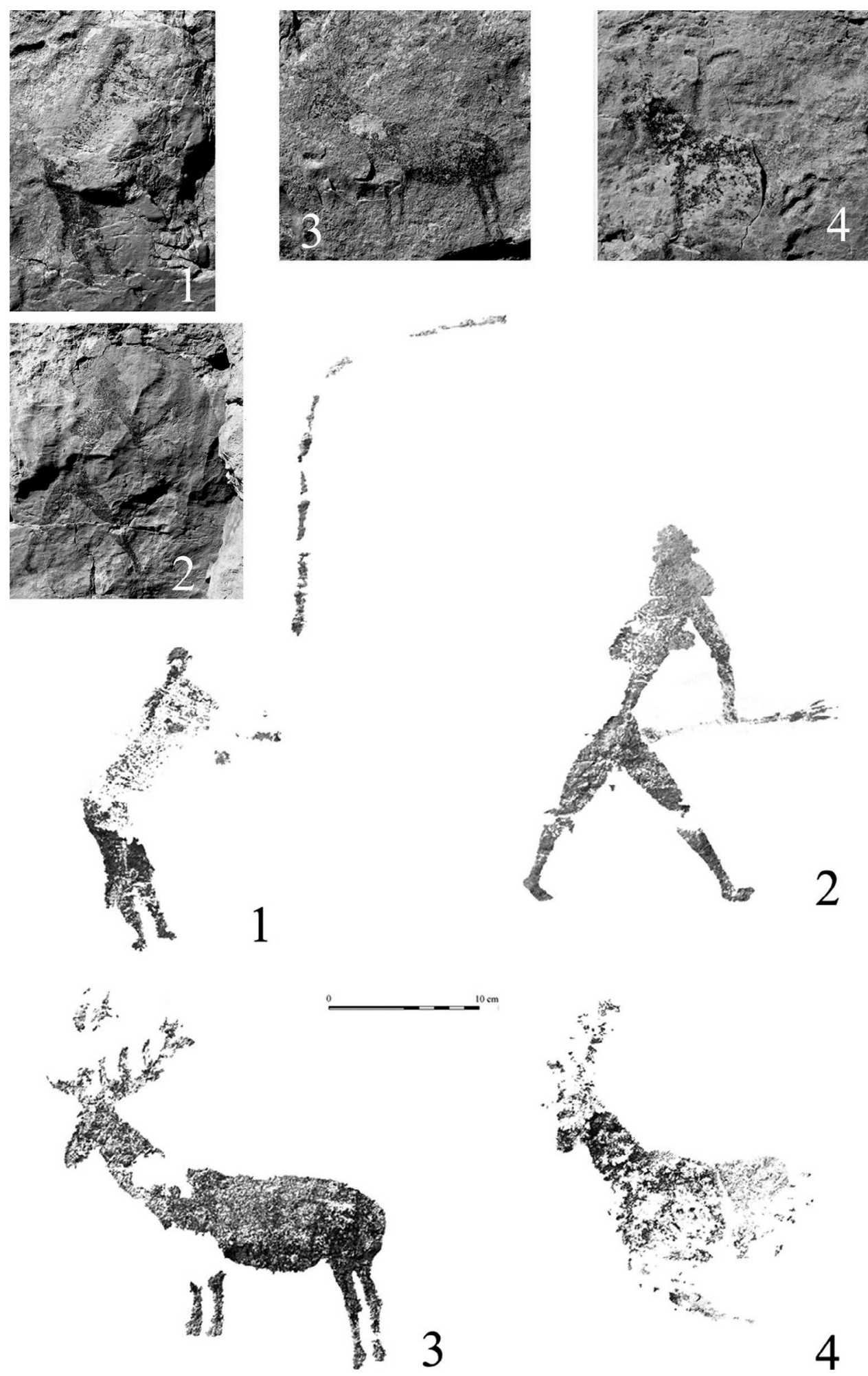

Lám. IV. Arriba: motivos pintados de Roca Benedí (Jaraba, Zaragoza). Abajo: calcos digitales de las representaciones rupestres. 1. motivo 2 (mujer con niño) y motivo 3 (trazos lineales). 2. motivo 1 (arquero). 3. motivo 4 (ciervo). 4. motivo 3 (ciervo). 
conchados del soporte pero la dirección en la que parece curvarse la barra vertical lleva a que propongamos que los dos fragmentos pertenezcan a una misma vara, curvada en su extremo. Su interpretación resulta difícil pues sólo conocemos el caso de una barra vertical de una longitud proporcionalmente semejante, sobre los cuartos traseros de un ciervo en la zona 3 de Solana de las Covachas (Alonso 1980).

\section{Motivo 4. Ciervo}

Se trata de un ciervo mirando a la izquierda que se halla ubicado a $14 \mathrm{~cm}$ a la izquierda de la mujer, dándose la espalda entre sí. Se halla muy mal conservado, lo que no permite identificar con total seguridad si se trata de una cabra o de un ciervo (Lám. IV.4). A favor de esta última interpretación aludimos a la presencia de restos de candiles transversales a las astas principales, la existencia del papo característico en el cuello y la similitud global al ciervo que representa el motivo . $^{\circ}$ 5. Sin embargo, la postura en ángulo agudo de su cabeza respecto al cuello, como preparándose para topar, resulta muy característica de las cabras levantinas, como es el caso de una del Frontón de los Cápridos (Almagro 1956), otra en la cueva de la Vieja de Alpera (Alonso y Grimal 1990), otra del Barranc de la Palla (Hernández et al. 1988) o dos de Villar del Humo (Ruiz 2005). De cualquier modo, dado que el trazo y el pigmento de los candiles es idéntico al del resto del animal, no parece que existiera un repintado del motivo, por lo que preferimos la primera interpretación, la de ciervo, para esta representación.

Dimensiones: desde el extremo superior del cuerno derecho hasta el extremo inferior del pecho el cuadrúpedo mide $17,6 \mathrm{~cm}$, teniendo $3,8 \mathrm{~cm}$ de anchura máxima en el cuello.

\section{Motivo 5. Ciervo}

Se trata de un ciervo de espléndida cornamenta y actitud estática mirando a la izquierda. Sus patas traseras parecen descansar sobre un reborde natural de la pared, limitando con sus cuernos otro situado en la parte superior, por lo que la figura queda bien enmarcada en el espacio disponible. Un trazo fino en negro perfila la silueta del animal rellenada a su vez en tinta plana. Presenta un desconchado en el arranque de sus patas de- lanteras y en la zona del cuello, pero su conservación y visibilidad puede calificarse de buena para lo que es habitual en el arte levantino (Lám. IV.3).

La figura completa alcanza los $24 \mathrm{~cm}$ de longitud máxima.

\section{LA MOVILIDAD DE LOS PINTORES LEVANTINOS: SU PROCEDENCIA A TRAVÉS DE LOS PARALELOS ESTILÍSTICOS}

La presencia de pinturas levantinas en la zona de Jaraba reviste un alto interés por cuanto indica patrones en la elección de los asentamientos como la preferencia por barrancos cerrados y con fuertes meandros, la selección de lugares con buena visibilidad y bien visibles, o la proximidad a afloramientos con aguas termales (6). Con todo, no es menos interesante el capítulo relativo a la movilidad de los pintores levantinos y su acceso a zonas hasta ahora desconocidas. Las novedades que aportan las pinturas de Jaraba son las siguientes:

1. Se amplía hacia el Oeste la dispersión del arte levantino (ya no tan levantino) puesto que se trata del abrigo más occidental ubicado en Aragón sólo superado en el Sur de la Península por el núcleo del alto Guadalquivir en Jaén (7) y algún conjunto del núcleo del Taibilla. En el centro, el extraño abrigo de Rillo de Gallo está situado sólo 2' más al Oeste, ya en la provincia de Guadalajara, documentándose en él un bóvido muy deteriorado que resulta compatible con un estilo levantino, tipo Albarracín (Balbín et al. 1989).

2. Aparece, al fin, arte levantino en el Sistema Ibérico de Zaragoza, provincia en la que sólo se

(6) La elección de determinados lugares como soporte de pinturas levantinas y esquemáticas está siendo tratado como tema de su Tesis Doctoral por parte de la geógrafa María Sebastián, becaria FPI asignada a nuestro vigente proyecto de investigación. Allí se ampliarán, sobre un soporte SIG, en la línea de trabajos anteriores como los de Cruz Berrocal (2004) o Fairén (2004).

(7) Los abrigos de la provincia de Cuenca, ubicados en términos como Henarejo, Minglanilla o Villar del Humo son también algo más occidentales que el de Jaraba. En cuanto a las pinturas halladas en el alto Guadalquivir, en la provincia de Jaén debe comentarse que su estilo no es demasiado ortodoxo dentro del arte levantino, siendo las más próximas las dos figuras humanas longilíneas de Arroyo de Hellín en el núcleo de Guadalmena (Soria et al. 2001) o el personaje de cabeza hipertrofiada asociado a una cabra del Engarbo I (Soria y López 1999). 
conocía el abrigo del Plano del Pulido de Caspe, ubicado en el límite con el término de Alcañiz (Teruel), dentro ya del Bajo Aragón.

3. Se localiza en una zona clave de comunicación ya que el río Mesa (y en general la cuenca del Jalón) supone el acceso a la Meseta Sur, enlazando con la cuenca del Tajo y el Tajuña. En este sentido resulta interesante por cuanto supone una aproximación al aislado abrigo de Rillo de Gallo, único ubicado en la provincia de Guadalajara, en la comarca de Molina de Aragón (Fig. 1). No olvidemos que el río Gallo, afluente del Tajo en su cabecera, dista sólo unos $10 \mathrm{~km}$ respecto al nacimiento del río Mesa, accediendo en una sola jornada a las pinturas de Roca Benedí.

Ahora bien, ¿de dónde procedían las gentes que pintaron las paredes de Jaraba? Es el momento de pararnos a pensar en los paralelos estilísticos de sus figuras, siendo los dos personajes humanos los que aportan mayor información, dada la poca variación que representan las figuras animales, siempre naturalistas en mayor o menor grado.

Somos conscientes de la complejidad de la cultura material en los grupos prehistóricos y de su papel en la sociedad, fruto de la cual surge la hipótesis que apunta la posibilidad de que estilos artísticos tan diferentes como el levantino y el esquemático fueran indistintamente empleados por las mismas sociedades neolíticas (Molina et al. 2003: 62). A pesar de esto, consideramos que existe un vínculo evidente, y no sólo parecido formal, que acerca a los motivos humanos de Roca Benedí a los observados en conjuntos del Maestrazgo turolense y castellonense. En este

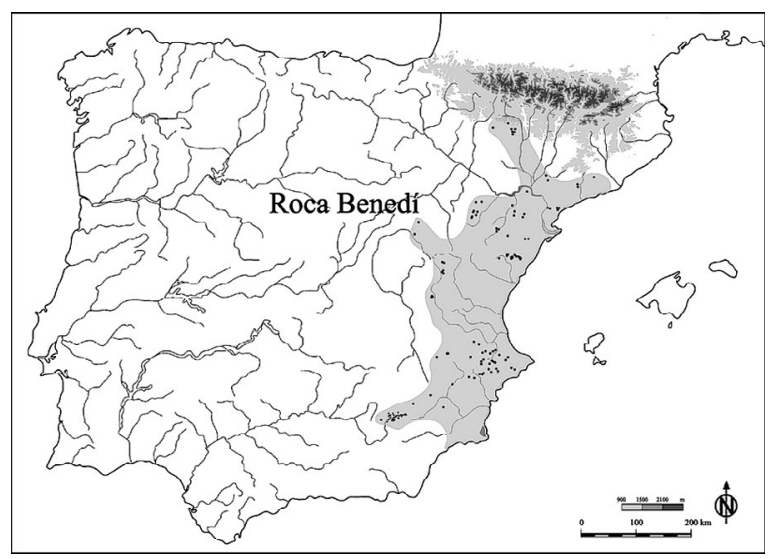

Fig. 1. Dispersión del arte rupestre levantino en la Península Ibérica. punto debemos hacer hincapié en la, hasta el momento, singularidad geográfica del conjunto que presentamos y en la abundante presencia de abrigos decorados con motivos del mismo tipo en los Maestrazgos, para establecer una posible movilidad estilística desde la que consideramos el área genésica hacia otras de expansión.

Consideramos mucho más probable que un núcleo genésico, en este caso de un tipo particular de antropomorfo levantino, cuente en sus cercanías con un mayor número de ejemplos, mientras que a medida que se dispersara iría decreciendo. Así, contamos con un número importante de conjuntos con motivos como el que nos ocupa en los Maestrazgos, mientras que a medida que se avanza hacia el Oeste (cuenca del río Martín) éste se ve reducido, para llegar a un único ejemplo en el extremo más occidental. No obstante, esta idea podría muy bien cambiar si en los próximos años el abrigo de Jaraba dejara de ser un unicum para conformar con otros conjuntos un basto núcleo de arte levantino a semejanza del existente en la zona oriental a la que aludimos.

En un reciente estudio sobre la variación estilística de la figura humana en el arte levantino aragonés asignamos a cuatro tipos principales y varios subtipos todas las figuras levantinas conocidas en Aragón (Utrilla y Martínez Bea 2007). Esta clasificación concuerda en lo principal con la basada en ejemplos del País Valenciano (Domingo 2006; Villaverde et al. 2006) cuya tabla comparativa aportamos (Tab. 1). Basándonos en estas dos clasificaciones vamos a intentar conocer la filiación estilística de Roca Benedí.

Sin embargo, nos resulta difícil asignar a un tipo concreto el arquero, ya que presenta características tan atenuadas que nos llevan a clasificarlo en un tipo mixto entre los dos primeros estilos. Por un lado se situaría cerca de los arquetipos estilizados, ya que posee una cierta esbeltez del talle, pero se trata de una figura naturalista y proporcionada lejos de los largos talles del horizonte Civil (Martínez Valle y Villaverde 2002). Encajaría mejor en el horizonte Centelles (Villaverde et al. 2006) pero tampoco puede hablarse claramente de un paquípodo, ya que el grosor de sus pantorrillas es correcto, acercándose más a los motivos 3 ó 21 de Valdelcharco (Beltrán 2002) o al desaparecido dels Secans (Cabré y Pérez Temprado 1921; Vallespí 1952). En el caso de Jaraba el arquero no presenta además los típicos calzones o zaragüelles ni la postura "al vuelo" que caracteri- 


\begin{tabular}{|c|c|c|}
\hline Valltorta & Valltorta y Maestrazgo & Aragón \\
\hline $\begin{array}{l}\text { Obermaier y } \\
\text { Wernert } 1919\end{array}$ & $\begin{array}{l}\text { Villaverde y Martínez Valle } 2002 \\
\text { Villaverde et al. } 2006 \\
\text { Domingo } 2006\end{array}$ & Utrilla y Martínez Bea 2007 \\
\hline \multirow[t]{2}{*}{ Paquípodo } & Horizonte Centelles & \multirow{2}{*}{$\begin{array}{l}\text { A. Arquetipo Robusto } \\
\mathrm{A}_{1} \text {. Paquípodo (tipo Garroso 37) } \\
\mathrm{A}_{2} \text {. Pseudopaquípodo (tipo Garroso 4) } \\
\mathrm{A}_{3} \text {. De cuerpo prominente (tipo Chaparros 68) }\end{array}$} \\
\hline & Tipo Tolls & \\
\hline \multirow[t]{2}{*}{ Cestosomático } & Horizonte Civil & $\begin{array}{l}\text { B. Arquetipo Estilizado } \\
\mathrm{B}_{1} \text {. Longilíneo (tipo Chaparros 28) } \\
\mathrm{B}_{2} \text {. Extralongilineo (tipo Chopo) } \\
\mathrm{B}_{3} \text {. De nalgas pronunciadas (tipo Arquero) }\end{array}$ \\
\hline & Tipo Mas d'en Josep & $\begin{array}{l}\text { Tipo Mixto } A_{1} / B_{1} \\
\text { Tipo Mixto } A_{1} / B_{2}\end{array}$ \\
\hline \multirow{2}{*}{ Nematomorfo } & \multirow{2}{*}{ Horizonte Lineal } & C-Linear (tipo Muriecho) \\
\hline & & D-Filiforme (tipo El Cerrao) \\
\hline
\end{tabular}

Tab. 1. Clasificación tipológica de la figura humana levantina.

za a las figuras paquípodas típicas del Bajo Aragón/Maestrazgo. Sin embargo, entroncaría bien con los marchadores tipo Centelles que se desplazan tranquilamente (Guillem y Martínez-Valle 2004) y que aparecen también en Los Chaparros 28 y 29 (Beltrán y Royo 1997), Cerrao 25 (Andreu et al. 1982; Beltrán 2005) o Racó d'en Perdigó (Viñas et al. 1983).

Otro elemento a resaltar es el espectacular tocado y la gran cabeza de forma triangular y peinado piriforme, morfología común entre los "marchadores" de la zona del Bajo Aragón/Maestrazgo (Garroso, Secans, Covacho Ahumado, Chaparros o La Vacada, por citar ejemplos aragoneses). En cuanto al penacho de plumas no encontramos paralelos idénticos, siendo los menos dispares los que portan los arqueros tripudos de los Chaparros, motivos 68 y 79 según Beltrán (2005) o la figura del padre con hijo de Remosi1lo, aunque éste se adscribe ya a un estilo subesquemático (Baldellou et al. 1996). En Levante citaremos los bien conocidos penachos de los arqueros de la cueva de la Vieja de Alpera (Alonso y Grimal 1990), poseedores además de gruesos muslos, aunque de distinta tipología al humano aquí estudiado. Pero, sin duda, son los marchadores de Centelles los que proporcionan el paralelo más próximo en el segundo arquero de la primera fila. Este personaje porta dos arcos (el suyo y el del compañero cargado con fardos) y lleva, sobre su cabeza de peinado piriforme, un tocado del que pende un penacho de plumas que caen, como en Jaraba, hacia su izquierda (Guillem y Martínez Valle 2004: 115, fig. 84, n. ${ }^{\circ}$ 2) (Lám. V).

Por último, la presencia de un brazalete sobre el codo izquierdo recordaría los que portan los arqueros yuxtapuestos al árbol de La Sarga, el del arquero del abrigo del Ciervo en Dos Aguas, en el Abric de Torrudanes (Villaverde et al. 2002), o el del abrigo del Sordo en Ayora (Barciela 2007). De nuevo podría encontrarse un paralelo en la figura que encabeza la marcha de los arqueros que se desplazan en Centelles, según parece desprenderse del calco de Guillem y Martínez Valle (2004: 115, fig. 84, n. ${ }^{\circ} 3$ ).

También tenemos que mirar a este abrigo para encontrar paralelos al motivo.$^{\circ} 2$, la mujer que porta un niño a su espalda (8). Este tema y composición se documentó por vez primera en los motivos 4 y 5 de la unidad 9 de los marchadores de Centelles (Guillem y Martínez Valle 2004, fig. 84, n. $^{\circ} 4$ y 5), pero existía ya en la figura 55 de Valdelcharco del Agua Amarga (Utrilla 2005: 358) donde Beltrán había descrito al personaje

(8) No conocemos paralelos temáticos y formales más allá de los ya referidos, sin que inicialmente hayamos considerado oportunos otros ejemplos para posibles escenas de mujeres "mantenedoras de sujetos" (Escoriza 2002: 73-76). Y no se han contemplado bien por no reproducir exactamente la misma temática -caso del abrigo II de Racó de Sorellets, en el que la mu- 

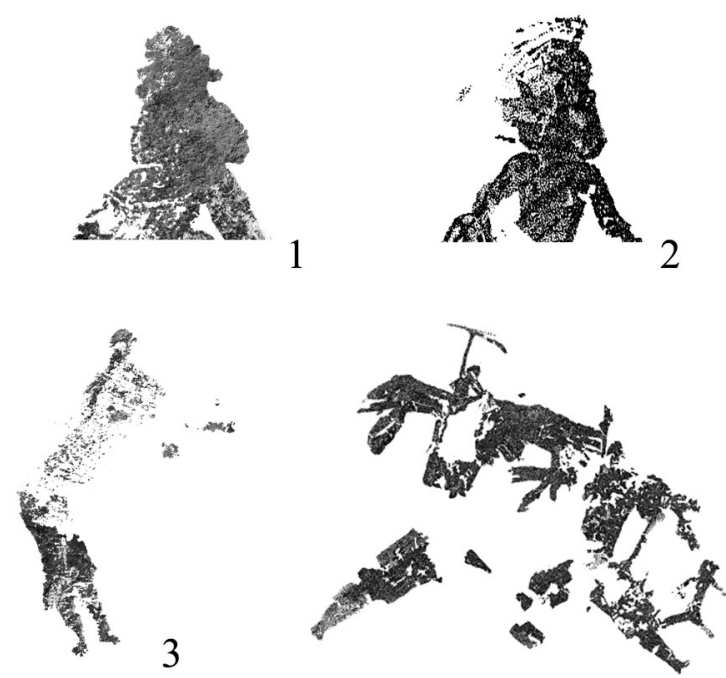

4
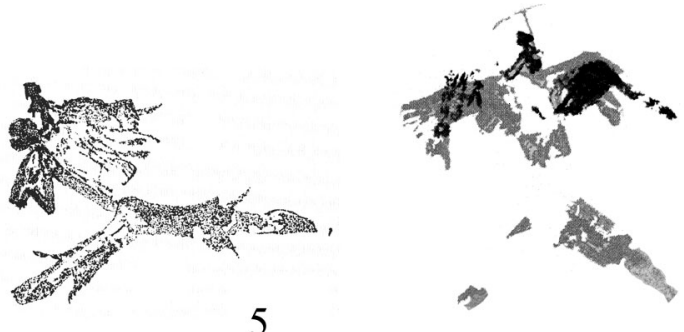

6

Lám. V. 1. Detalle de los tocados de los arqueros de Roca Benedí (Zaragoza) (1) y Centelles (Castellón) (2). Paralelos de mujeres llevando niños: 3. Roca Benedí. 4. Centelles (según Guillem y Martínez Valle 2004). 5. Valdelcharco (Teruel) (según Beltrán 2002) 6. La Saltadora (Castellón) (según Domingo et al. 2007).

como "cargado con una cría de animal" (9) añadiendo que "parece más de acuerdo con un rito pastoril que con uno de caza" (Beltrán et al. 2002: 128). De nuevo podría rastrearse el tema en el motivo 32-VII de La Saltadora (Domingo et al. 2007), dentro del núcleo de la Valltorta. En todas ellas el niño, siempre con cabeza muy erguida, se sujeta con sus manos al fardo que porta su madre,

jer sentada tiene a un niño sobre las rodillas o de Caídas del Salbime de Mazaleón, con la misma escena maternal- o bien por ser más que dudosos en su interpretación temática. Podrían representar perfectamente mochilas como es el caso del abrigo de los Trepadores en Alacón (Teruel) o del abrigo del Ciervo en Dos Aguas (Valencia).

(9) No obstante, señala Beltrán (2000: 74) que su "colaborador José Royo piensa que lo que carga sobre los hombros de este personaje son pieles y el peso, en su opinión, podría corresponder al de un hombrecillo". Esta sería la primera vez que en la literatura se deja entrever la posibilidad de que sea un niño (un hombrecillo) el que cabalga sobre las pieles. pareciendo responder a un mismo esquema compositivo (Lám. V). En los tres casos (Centelles, Saltadora y Valdelcharco) estamos ante una misma provincia estilística.

Por otra parte, la presencia en sí de una figura femenina, con marcadores indirectos del sexo como las faldas y la inclinación del cuerpo soportando peso (Escoriza 2002: 72 y 2005: 730) que permiten identificarla como tal, puede ser significativa a la hora de valorar la filiación de las pinturas de Roca Benedí. En efecto, la mujer está prácticamente ausente en el Alto Aragón (10), pero, en cambio, tiene una notable representación en el grupo formado por el Bajo Aragón/Maestrazgo-Valltorta/Bajo Ebro, a cuyos estilos antiguos parece vincularse el conjunto de Jaraba. En esta zona, llaman especialmente la atención las mujeres de Centelles donde en un primer recuento supondrían un $20 \%$ del total de figuras (Guillem y Martínez Valle 2004; Martínez Valle y Guillem 2006; Villaverde et al. 2006). Se representan con pechos bien marcados y pantorrillas gruesas y suelen plasmarse vestidas con amplios calzones o faldas de picos hasta la pantorrilla, tal como aparece en el arquetipo de la supuesta "danza fálica" de Cogull (Breuil 1909).

En el Bajo Aragón se computan ejemplos en Valdelcharco del Agua Amarga, el motivo femenino de grandes dimensiones y también inclinada hacia adelante (Beltrán 2002); en Los Chaparros (en este caso desnuda y en avanzado estado de gestación) (Beltrán y Royo 1997); o en el abrigo del Arquero de Ladruñán, haciendo pareja con la figura que da nombre al abrigo (Ripoll 1961). El mismo tipo longilíneo, con piernas y caderas bien marcadas, aparece en el Grupo de Bajo Aragón/Maestrazgo /Bajo Ebro: por ejemplo, en tres mujeres de Cova Remigia (Porcar et al. 1935), otras tantas en Polvorín/Rossegadors (Vilaseca 1947; Mesado 1989) y una más en el abrigo A de Palanques (Mesado 1995; Alonso y Grimal 2001). Junto a los tipos claramente longilíneos de Valdelcharco aparecen otras mujeres más proporcionadas, como la del Racó Gasparo (Porcar 1965; Viñas 1982), con falda hasta las rodillas, nalgas muy prominentes y piernas juntas y gruesas que recuerdan la figura femenina de Jaraba.

(10) Es posible que alguna de las 37 figuras humanas lineares de Muriecho pudiera ser considerada como femenina, pero la falta de detalles diferenciadores determinan que tal clasificación no sea concluyente. 
Sin embargo, en todos los casos citados las mujeres presentan un talle muy delgado, lo que no ocurre en la figura femenina de Roca Benedí que ofrece un tórax grueso. Por desgracia el grado de conservación del pigmento no permite establecer si se trata de un tórax simplemente naturalista, al estilo del de la figura yacente $n .^{\circ} 2$ de los Arqueros Negros de Alacón (Herrero et al. 1995), o si se trata en realidad de un embarazo comparable al clarísimo de la mujer de Los Chaparros de Albalate (11) (Beltrán y Royo 1997; Beltrán 2005).

De cualquier modo, todos los ejemplos femeninos de similar tipología nos encaminan de nuevo hacia la misma provincia: el que denominamos grupo II de Bajo Aragón/Maestrazgo /Bajo Ebro, un claro ejemplo de articulación territorial con características específicas que ya hemos señalado en otras publicaciones (Utrilla 2005: 356-360; Martínez Bea 2006; Utrilla y Martínez-Bea 2006: 30-34, mapas 3 y 5).

En resumen, las dos figuras humanas presentan una mayoría de rasgos que llevan a acercarlos a priori al arquetipo robusto $\mathrm{A}_{1}$ o grupo Centelles, a pesar de que no puedan ser denominados como paquípodos estrictos $\mathrm{y}$, en menor medida, al arquetipo estilizado $\mathrm{B}_{1}$, longilíneo o grupo Civil. Así, si nos fijamos en las pautas de modelado anatómico establecidas por Domingo (2005: 400, fig. 24) para la región castellonense de Maestrazgo/Valltorta, apreciamos que todos los rasgos observados en el motivo 1 de Roca Benedí se dan en el grupo Centelles: la cabeza piriforme, que aparece en 34 casos; la ausencia de cuello, detallado en 27; el torso triangular con cintura estrecha, en 35 ocasiones; y las piernas naturalistas bien modeladas (aunque gruesas), en 48. En el arquero de Jaraba no se cumple este último requisito, pero sí podría asignarse a la mujer que presenta pantorrillas algo más gruesas.

Si nos atenemos a la tabla de los ornamentos (Domingo 2005: 401, fig. 25) el tocado de plu-

(11) Es posible incluso que el citado abrigo de los Arqueros Negros posea a su vez una nueva figura de mujer embarazada a juzgar por la foto que reproduce Beltrán (2005: fig. 91) definida como "gran figura roja con dos ondulaciones". No obstante, en este caso lo reseñamos sólo como sugerencia, ya que únicamente se documenta la prominente barriga y, con muchas dudas, los dos pechos. No son visibles ni la cabeza ni las piernas. La misma indefinición se aprecia en una supuesta figura embarazada que cita Beltrán y Royo (1994: 35) en el abrigo de la Higuera de Estercuel. En cambio, en el caso de la figura desnuda de los Chaparros son bien perceptibles cabeza, pechos, brazos, piernas y barriga, la cual nada tiene que ver con la de los arqueros tripudos del mismo abrigo. mas es más propio del grupo Civil ( 8 casos frente a solo 1 en Centelles), siendo las antenas más específicas de Centelles (8). También pertenece a este último grupo la carga con niño ( 3 casos) y los brazaletes (12) exclusivos éstos de Centelles. Por último, las jarreteras de nuestro arquero aparecen en 19 casos en Centelles (no aparecen en Civil) y el pantalón ancho que quizá lleve la mujer, en 4.

En el apartado de armamento no se aprecia distinción entre los grupos de Centelles y Civil por lo que a cualquiera de ellos convendría la representación de Roca Benedí, por otra parte muy mal conservada. El arco en Jaraba no presenta cuerda, suponiendo 13 casos (todos) en Centelles y 30 en Civil, mientras que las flechas son de ápice simple ( 6 casos en Centelles y 14 en Civil) y presentan una emplumadura lanceolada: 18 casos en Centelles (todos) y 15 en Civil (Domingo 2005: 403, fig. 26).

En cuanto a la temática, la pareja que se desplaza, él con arco y flechas y ella con niño a la espalda, es característica del estilo Centelles, pero no la presencia de los dos ciervos que no encajan en el grupo, donde no aparecen motivos animales asociados. Sin embargo, tampoco puede asegurarse que los cérvidos formen escena en el conjunto zaragozano con los dos antropomorfos, ya que se dan mutuamente la espalda, a pesar de que el pigmento negro y el trazo utilizado en todas las figuras parece indicar que fueron realizadas en un mismo momento. Hay que llegar al tipo Civil para encontrar ciervos asociados a figuras humanas.

Por otra parte, los ciervos de Roca Benedí presentan una similitud formal con el ciervo central del Plano del Pulido de Caspe (Eiroa 1984-1985) por su forma de la cabeza, postura del cuerpo y orientación, pero en este caso forma grupo con otro ciervo macho y dos ciervas sin que exista presencia humana en la hornacina. Sin embargo, no hay que descartar que exista también en Plano del Pulido una figura humana longilínea pintada en rojo a la derecha de la hornacina, la cual se encuentra parcialmente cubierta por precipitaciones negras y todavía pendientes de su limpieza por parte del restaurador.

(12) Hay figuras humanas en el entorno de los grandes ciervos de Valdelcharco o Frontón de los Cápridos pero son de tipo filiforme y no parece que tengan nada que ver con los ciervos. En el caso del Garroso una torpe figura sí parece vinculada a sus cuartos traseros pero podría tratarse de una escena de acumulación (Utrilla y Martínez-Bea 2005-2006). 
La similitud de los ciervos de Roca Benedí es bastante menor con respecto a otros cérvidos levantinos del Bajo Aragón/Maestrazgo: aparecen aislados sin figura humana asociada a ellos en la Roca dels Moros de Calapatá (Breuil y Cabré 1909; Cabré 1915), Cañada de Marco (Beltrán y Royo 1996), Valdelcharco, El Garroso y Frontón de los Cápridos (12) y con figuras humanas estilizadas quizá formando escena en Els Gascons (Cabré 1915), Los Chaparros (Beltrán y Royo 1997) y Barranco Hondo, en los 3 casos del tipo de nalgas pronunciadas (Utrilla y Villaverde 2004), en El Chopo, con tipos extralongilíneos (Picazo et al. 2001-2002), y en Cantalar I (Bea y Domingo e.p.). En la zona del Vero aparece aislado en Chimiachas (Baldellou et al. 1986) y Labarta con 3 ejemplares (Baldellou et al. 1986); con otros animales en Litonares (4) (Baldellou 1984-1985) y Regacéns (1) (Baldellou et al. 1993b), y asociado en escenas a figuras humanas del tipo linear en Arpán (4) (Baldellou et al. 1993a), Muriecho (4) (Baldellou et al. 2000) y la Raja (3) (Baldellou et al. 1997). En Albarracín aparece aislado en abrigo del Ciervo y Figuras Diversas, y junto a otros animales y figuras humanas de tipo longilíneo y linear en Olivanas (Piñón 1982).

En la zona castellonense encontramos de nuevo dos ejemplos similares en el abrigo de la Saltadora, los motivos 11 y 12 , cérvidos pintados ambos en negro aunque, en este último caso, presentan cuerpos listados (Domingo et al. 2007). Otras dos figuras de arqueros negros, muy estilizados, se documentan en Rossegadors/Polvorín (Vilaseca 1947). También se localiza el color negro en la falange de guerreros con arcos levantados del Cingle de la Mola Remigia (color pardo negruzco) y en diversos motivos de la Cova Remigia, como un bóvido (n. ${ }^{\circ} 3$ ) de la cuarta cavidad, un jabalí con flechas (n. $\left.{ }^{\circ} 85\right)$ de la quinta y una interesante escena de ejecución en la que la falange de arqueros (vivos) se pintan en rojo (n. ${ }^{\circ}$ 91) mientras que el ejecutado (muerto) se pinta en negro (n. ${ }^{\circ}$ 92) (Porcar et al. 1935). Todas ellas, junto a otras inéditas de Centelles, se ubican dentro del mismo grupo geográfico.

Por otra parte el uso del pigmento negro en el arte levantino aragonés es desigual en los tres núcleos geográficos. En el núcleo oscense se documenta sólo un tono grisáceo en uno de los ciervos de Labarta (Baldellou et al. 1986), mientras que en el Bajo Aragón conocemos cuatro estaciones, tres de ellas en el término de Alacón. Así, en el abrigo de El Garroso, el más destacado, el color negro se documenta en un conjunto de motivos humanos lineales que portan discos ubicados en la zona izquierda del panel, los motivos 20 a 27 según Beltrán (2005). En este mismo abrigo se observa en un personaje longilíneo (el número 3 ) que se superpone a otro similar (el número 2), éste en color rojo, y que se infrapone a otro motivo humano "pseudopaquípodo" o Tipo Tolls (el número 4). Entre las representaciones animales encontramos cuatro motivos más en color negro distribuidos por todo el panel, los números 17, 30, 35 y 42 (Beltrán 2005). En el abrigo de los Arqueros Negros aparecen representados en negro hasta una veintena de pequeños arqueros filiformes (Herrero et al. 1995) que acechan a la gran figura humana yacente pintada en rojo. En el cercano abrigo del Frontón de los Cápridos aparece en negro un cérvido (motivo 26) y dos figuritas humanas filiformes (motivos 12 y 13), si bien este color fue empleado también para siluetear las cornamentas y pezuñas de algunos ejemplares de cabras. Por último, en el conjunto rupestre del Hocino de Chornas se reconocen un total de cuatro figuraciones humanas en color negro, entre ellas una de un arquero prognato. Esta figura, conocida como "el negroide" (Burillo y Picazo 1981: fig. 2), presenta rasgos comunes a los dos motivos humanos de Roca Benedí: respecto al arquero masculino unas proporciones correctas y una buena delineación de pies y pantorrillas y respecto a la mujer un torso grueso de tendencia rectangular, dado que éste podría vislumbrarse en la figura femenina a pesar de la mala conservación del pigmento.

Existe también una importante presencia de figuras negras en el núcleo de Albarracín, quizá debido al condicionamiento del soporte rojo proporcionado por el rodeno que lleva a ensayar, además del rojo tradicional, otros colores no habituales como el blanco o el negro. Hemos computado 25 motivos pintados en este color pertenecientes a 8 abrigos, de los que 23 se ubican en el término de Albarracín y 2 en el de Tormón. En el primer grupo se documentan un arquero filiforme en el Prado del Navazo y cinco bóvidos negros: en Cocinilla del Obispo (1), Figuras Diversas (1) Medio Caballo (2) y Toro Negro (1); en término de Tormón se halla el famoso bóvido de la Ceja de Piezarrodilla que repinta en negro un anterior toro blanco y una cabra en la Paridera del Tormón 
donde existe una figura humana que recuerda la tipología del arquero de Jaraba. Se trata de un antropomorfo pintado en blanco con torso de tendencia triangular que presenta peinado piriforme tocado con dos o tres plumas y que porta en su mano un posible boomerang, bidente para Beltrán (1997: 47). Por último, en las Olivanas, también en término de Albarracín, aunque en la lejana zona del barranco del Pajarejo, se documentan 17 figuras negras: diez bóvidos, un cérvido, un équido, tres cuadrúpedos indeterminados y dos figuras humanas longilíneas (Piñón 1982).

Sin embargo, la tipología de la figura humana en la zona de Albarracín se acerca más en su conjunto a los tipos tardíos, lineares y filiformes, con la excepción de algunas figuras de las Olivanas, entre ellas el arquero del "sombrero de copa" (en pardo rojizo) que presenta proporciones correctas, bien modeladas piernas, torso naturalista y espectacular tocado, el cual sería el que más se parece (y no mucho) a los tipos de Jaraba.

\section{CONCLUSIONES}

La importancia del hallazgo que presentamos se fundamenta en distintos aspectos que conciernen a cuestiones estilísticas, cromáticas y territoriales. En síntesis, las pinturas de Roca Benedí se perfilan como una extensión del núcleo Bajo Aragón/Maestrazgo/Bajo Ebro caracterizado por el predominio de estilos antiguos (arquetipos robustos y estilizados), la presencia significativa de la mujer y temas exclusivos como son los arqueros "al vuelo" o los marchadores, cuyas mujeres portan niños a su espalda.

Con todo, y a pesar de que es en los conjuntos rupestres del núcleo apuntado donde encontramos los principales paralelos estilísticos, las pinturas de Roca Benedí presentan algún rasgo singular que las individualizan dentro del arte levantino más clásico, como es el uso único en la confección de los motivos del pigmento negro. Asimismo, no conocemos paralelos para la convención del pantalón ceñido y atado a la pantorrilla que lleva el arquero.

En cuanto a la ubicación de las pinturas se debe destacar que ocupan un lugar de especial significación en la articulación del territorio inmediato, tanto desde el punto de vista de su localización dentro del barranco -en el meandro de mayor desarrollo y en el farallón del que se tiene mejor visibilidad desde diferentes puntos del recorrido- como por su cercanía a las aguas termales de Jaraba. El cañón, en cuyo centro se sitúan las pinturas, parece responder a la tipología del conocido Barranc de la Valltorta, si bien, por el momento, no se ha podido documentar la misma concentración de estaciones decoradas.

Pero quizá, el aspecto más destacado del nuevo hallazgo resida en su localización geográfica, que extiende significativamente hacia el Oeste el territorio de expansión del arte levantino. La distancia de unos $200 \mathrm{~km}$ existente entre Roca Benedí y los conjuntos rupestres más afines desde un punto de vista estilístico y temático subraya nuevamente la importante movilidad de los grupos prehistóricos creadores del arte levantino, abriendo además la posible existencia de otros conjuntos rupestres en la vía natural de acceso a la Meseta, la cuenca del Jalón.

Nuestro vigente proyecto de investigación acerca de la Movilidad de las sociedades prehistóricas en el Valle del Ebro tiene todo un reto ante sí.

\section{BIBLIOGRAFÍA}

Almagro, M. 1956: "Las pinturas rupestres del Bajo Aragón”. En M. Almagro, A. Beltrán y E. Ripoll: Prehistoria del Bajo Aragón. Instituto de Estudios Turolenses. Zaragoza: 41-95.

Alonso, A. 1980: El conjunto rupestre de Solana de las Covachas, Nerpio (Albacete). Instituto de Estudios Albacetenses. Albacete.

Alonso, A. y Grimal, A. 1990: Las pinturas rupestres de la Cueva de la Vieja. Ayuntamiento de Alpera y Diputación de Albacete. Alpera.

Alonso, A. y Grimal, A. 1994: "El Arte Levantino o el 'trasiego' cronológico de un Arte prehistórico". Pyrenae 24: 51-70.

Alonso, A. y Grimal, A. 2001: "Acerca del estudio del arte levantino". Millars 24: 87-110.

Andreu, J.; Ariño, A.; Perales, P.; Picazo, J. y Sancho, A. 1982: "Las pinturas levantinas de El Cerrao (Obón, Teruel)". Kalathos 2: 83-116.

Baldellou, V. 1984-1985: "El arte rupestre post-paleolítico de la zona del río Vero (Huesca)". Ars Prehistorica III-IV. Editorial Ausa. Sabadell: 111-137.

Baldellou, V.; Painaud, A. y Calvo, M. ' J. 1986: "Dos nuevos covachos con pinturas naturalistas en el Vero (Huesca)". Estudios en Homenaje al Profesor Antonio Beltrán Martínez: 115-133. Universidad de Zaragoza. Zaragoza. 
Baldellou, V.; Painaud, A.; Ayuso, P. y Calvo, M. ${ }^{\mathrm{a} J}$. 2000: "Las pinturas rupestres de la partida de $\mathrm{Mu}-$ riecho (Colungo y Bárcabo. Huesca)". Bolskan 17: 33-86.

Baldellou, V.; Painaud, A.; Calvo, M.'J. y Ayuso, P. 1993b: "Las pinturas rupestres de la cueva de Regacéns (Asque, Colungo. Huesca)". Bolskan 10: 97-144.

Baldellou, V.; Painaud, A.; Calvo, M.'J. y Ayuso, P. 1996: "Las pinturas rupestres de Remosillo, en el congosto de Olvena (Huesca)". Bolskan 13 (II): 173-215.

Baldellou, V.; Painaud, A.; Calvo, M.' J. y Ayuso, P. 1997: "Las pinturas rupestres de los covachos de La Raja (Santa Eulalia de la Peña, Nueno. Huesca)". Bolskan 17: 29-41.

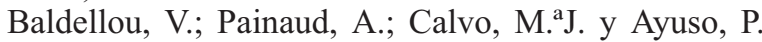
1993a: "Las pinturas rupestres del barranco de Arpán (Asque-Colungo. Huesca). Bolskan 10: 31-96.

Barandiarán, I. 1975: "Revisión estratigráfica de la cueva de la Mora (Somaén, Soria)". Noticiario Arqueológico Hispánico 3: 9-72.

Barciela, V. 2007: "La representación de elementos de adorno en el arte rupestre de La Marina Alta". Actes del 4t Congrés d'Estudis de La Marina Alta (La Marina 2003): 85-108. Marina Alta.

Bea, M. y Domingo, R. (e.p.): "Las pinturas levantinas del abrigo de Cantolar I (Villarluengo-Montoro de Mezquita, Teruel)". Sagvntvm 41.

Beltrán, A. 1997: "Las pinturas prehistóricas de la Paridera de Tormón". Arqueología Aragonesa 1994: 45-50.

Beltrán, A. 2000: “El portador de animal núm. 55 del abrigo 'levantino' de Val del Charco: rectificaciones sobre una figura humana mal publicada". Cuadernos de Prehistoria y Arqueología Castellonenses 21: 69-75.

Beltrán, A. (dir.) 2002: Las pinturas rupestres del abrigo de Val del Charco del Agua Amarga de Alcañiz. Prames. Zaragoza.

Beltrán, A. (dir.) 2005: Corpus de arte rupestre del Parque Cultural del Río Martín. Asociación Parque Cultural del Río Martín. Zaragoza.

Beltrán, A. y Royo, J. 1994: El abrigo de La Higuera, o del Cabezo del Tío Martín en el Barranco de Estercuel. Alcaine, Teruel. Avance a su estudio. Colección "Guías de Aragón” 19. Zaragoza.

Beltrán, A. y Royo, J. 1996: Las pinturas rupestres de la Cañada de Marco, Alcaine (Teruel). Colección Parque Cultural del Río Martín. Zaragoza.

Beltrán, A. y Royo, J. 1997: Los abrigos prehistóricos de Albalate del Arzobispo (Teruel). Revisión del abrigo. Colección Parque Cultural del Río Martín. Zaragoza.

Breuil, H. 1909: "Les peintures rupestres du bassin inférieur de l'Ebre. II. Les fresques à l'air libre de
Cogul, province de Lérida (Catalogne)". L'Anthropologie XXI: 369-371.

Breuil, H. y Cabré, J. 1909: “Les peintures rupestres du Bassin inférieur de l'Èbre. I. Les rochers peints de Calapatá à Cretas". L'Anthropologie XX: 1-21.

Burillo, F. y Picazo, J.V. 1981: "Nuevo hallazgo de pinturas levantinas en el barranco del Hocino de Chornas. Obón (Teruel)". Kalathos 1: 75-91.

Cabré, J. 1915: Arte rupestre en España. Memoria 1 de la Comisión de Investigaciones Paleontológicas y Prehistóricas. Junta para la Ampliación de Estudios e Investigaciones Científicas. Madrid.

Cabré, J. y Pérez Temprado, L. 1921: "Nuevos hallazgos de arte rupestre en el Bajo Aragón”. Boletín de la Real Sociedad Española de Historia Natural. Tomo del 50 Aniversario: 276-286.

Cruz Berrocal, M. ' 2004: "La investigación del arte rupestre desde la geografía: la pintura neolítico en el ámbito mediterráneo de la Península Ibérica". Trabajos de Prehistoria 61 (2): 41-62.

Davidson, I. 1989: La economía del final del Paleolitico en la España Oriental. Servicio de Investigaciones Prehistóricas, Trabajos varios 85. Valencia.

Domingo, I. 2005: Técnica y ejecución de la figura en el arte rupestre levantino. Hacia una definición actualizada del concepto de estilo: validez y limitaciones. Universidad de Valencia. Valencia. http:/www.tdx.cat/TDX-0327106-18100888

Domingo, I. 2006: "La figura humana, paradigma de continuidad y cambio en el Arte Rupestre Levantino". Archivo de Prehistoria Levantina XXVI: 161-191.

Domingo, I.; López, E.; Villaverde, V. y Martínez Va1le, R. 2007: Los abrigos VII, VIII y IX de Les Coves de La Saltadora. Monografías del Instituto de Arte Rupestre 2. Tírig. Museu de la Valltorta, Generalitat Valenciana. Valencia.

Eiroa, J. 1984-1985: "El Plano del Pulido: un nuevo abrigo con pinturas de estilo levantino en Caspe (Zaragoza)". Ars Praehistorica III/IV. Editorial Ausa. Sabadell: 261-269.

Escoriza, T. 2002: La representación del cuerpo femenino. Mujeres y arte rupestre levantino del Arco Mediterráneo de la Península Ibérica. British Archaeological Reports. International Series 1082. Oxford.

Escoriza, T. 2005: "Producción y trabajo femenino en las representaciones rupestres levantinas". III Congreso del Neolítico de la Península Ibérica (Santander, 5-8 octubre 2003): 729-738. Santander.

Fairén, S. 2004: “¿Se hace camino al andar? Influencia de las variables medioambientales y culturales en el cálculo de caminos óptimos mediante SIG". Trabajos de Prehistoria 61 (2): 25-40.

Fortea, F.J. 1974: "Algunas aportaciones a los problemas del Arte Levantino". Zephyrus XXV: 225-257. 
Fortea, F.J. y Aura, E. 1987: "Una escena de vareo en La Sarga (Alcoy). Aportaciones a los problemas del arte levantino". Archivo de Prehistoria Levantina XVII: 97-120.

Guillem, P.M. y Martínez Valle, R. 2004: “Las figuras humanas del abrigo del Barranco Hondo en el contexto del Arte Levantino del Bajo Aragón-Maestrazgo". En P. Utrilla y V. Villaverde (eds.): Los grabados levantinos del Barranco Hondo (Castellote, Teruel). Gobierno de Aragón. Zaragoza: 105-122.

Hernández, M.S. y Centre d'Estudis Contestans 1982: "Consideraciones sobre un nuevo tipo de Arte prehistórico". Ars Prehistorica 1. Editorial Ausa. Sabadell: 179-187.

Hernández, M.S. y Martí, B. 2001: “El arte rupestre de la fachada mediterránea: entre la tradición epipaleolítica y la expansión neolítica”. Zephyrus LIII-LIV: 241-265.

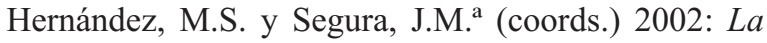
Sarga. Arte Rupestre y Territorio. Ajuntament d'Alcoi y Caja de Ahorros del Mediterráneo. Alcoi.

Hernández, M.S.; Ferrer, P. y Catalá, E. 1988: Arte Rupestre en Alicante. Fundación Banco Exterior, Banco de Alicante Grupo Banco Exterior. Alicante.

Herrero, M.A.; Loscos, R. y Martínez, R. 1995: “Informe sobre los nuevos abrigos con pinturas rupestres en cerro Felío (Alacón, Teruel)". Arqueología Aragonesa 1993: 13-20.

Kunst, M. y Rojo, M. 1999: "El Valle de Ambrona: un ejemplo de la primera colonización Neolítica de las tierras del Interior Peninsular'. Saguntum Extra 2: 259-270.

Llavori de Micheo, R. 1988-1989: "El arte postpaleolítico levantino de la Península Ibérica. Una aproximación sociocultural al problema de sus orígenes". Ars Prehistorica VI-VII. Editorial Ausa. Sabadell: 145-156.

Martí, B. y Hernández, M.S. 1988. El Neolític Valencia. Art rupestre i cultura material. Servei d'Investigació Prehistórica de la Diputació de Valencia. Valencia.

Martínez Bea, M. 2004: “La estación del Barranco Hondo en su espacio geográfico y social". En P. Utrilla y V. Villaverde (coords.): Los grabados levantinos del Barranco Hondo (Castellote, Teruel). Gobierno de Aragón. Zaragoza: 87-103.

Martínez Bea, M. 2006: Variabilidad estilistica y distribución territorial del arte rupestre levantino: el ejemplo de La Vacada (Castellote, Teruel). Universidad de Zaragoza. Zaragoza.

Martínez Bea, M. 2008: “Arte rupestre de Albarracín: la excepcionalidad de un conjunto interior". En M.S. Hernández, J.A. Soler, y J.A. López (eds.): Actas del IV Congreso de Neolítico Peninsular. (Alicante, 27-30 noviembre 2006): 141-148. Alicante.
Martínez Bea, M. 2009: Las pinturas rupestres del abrigo de La Vacada (Castellote, Teruel). Monografías Arqueológicas 43. Universidad de Zaragoza. Zaragoza.

Martínez Valle, R. y Villaverde, V. (coords.) 2002: La Cova dels Cavalls en el Barranc de la Valltorta. Monografías del Instituto de Arte Rupestre 1. Tírig. Museu de la Valltorta, Generalitat Valenciana. Valencia.

Martínez Valle, R. y Guillem, P. 2006: “Dónde están las mujeres. Una aproximación a la distribución de las figuras femeninas de estilo levantino en el Parque Cultural de Valltorta-Gasulla". En M. 'J. de Pedro, J.A. Alcántara y C. Marcilla (eds.): Las mujeres en la Prehistoria. (Valencia, 2006): 51-62. Valencia.

Mateo, M.A. 2002: “La llamada 'fase pre-levantina' y la cronología del Arte rupestre Levantino. Una revisión crítica". Trabajos de Prehistoria 59 (1): 49-64.

Mesado, N. 1989: "Nuevas pinturas rupestres en la Cova dels Rossegadors (La Pobla de Benifassà, Castellón)". Sociedad Castellonense de Cultura. Serie Arqueológica VII. Castellón.

Mesado, N. 1995: Las pinturas rupestres naturalistas del abrigo A del Cingle de Palanques: (Els Ports, Castelló). Diputación de Castellón. Castellón.

Molina, L.; García Puchol, O. y García Robles, M. ${ }^{\text {R }}$. 2003: "Apuntes al marco crono-cultural del arte levantino: Neolítico vs neolitización”. Saguntum 35: 51-67.

Picazo, J.; Loscos, R.; Martínez Bea, M. y Perales, M.P. 2001-2002: "Las pinturas rupestres de la Cueva del Chopo (Obón, Teruel)". Kalathos 20-21: 27-83.

Piñón, F. 1982: Las pinturas rupestres de Albarracín (Teruel). Monografías del Centro de Investigación y Museo de Altamira 6. Ministerio de Cultura. Santander.

Porcar, J.B. 1965: "Las pinturas del Racó de Gasparo". Boletín de la Sociedad Castellonense de Cultura XLI: 176.

Porcar, J.B.; Obermaier, H. y Breuil, H. 1935: Excavaciones en la Cueva Remigia (Castellón). Junta Superior del Tesoro Artístico. Sección de excavaciones. Madrid.

Redondo, J.C.; Bueno, P.; Jiménez, P.; Fernández, J.A.; Balbín, R. de; Pino, E. y Alcolea, J. 1989: “El abrigo rupestre del Llano, Rillo de Gallo, Molina de Aragón". XIX Congreso Nacional de Arqueología 2 (Castellón, 1987): 179-194. Zaragoza.

Ripoll, E. 1961: Los abrigos pintados de los alrededores de Santolea (Teruel). Monografías de Arte Rupestre. Arte Levantino 1. Barcelona.

Rojo, M; Garrido, R; Morán, I y Kunst, M. 2004: “El campaniforme en el valle del Ambrona (Soria, España): dinámica de poblamiento y aproximación a 
su contexto social". En M. Besse y J. Desideri (eds.): Graves and Funerary rituals during the Late Neolithic and the Early Bronze Age in Europe (2700-200BC). British Archaeological Reports 1284. Archaeopress. Oxford: 5-13.

Ruiz, J.F. 2005: "Peña del Escrito II (Villar del Humo, Cuenca). Revisión de un abrigo clásico". En M. Hernández y J. Soler (eds.): Arte rupestre en la España mediterránea (Alicante, 2004): 235-250. Alicante.

Soria, M. y López Payer, M. 1999: Los abrigos con arte rupestre levantino de la Sierra de Segura. Patrimonio de la Humanidad. Arqueología Monografías. Consejería de Cultura. Jaén.

Soria, M.; López Payer, M.G. y Zorrilla, D. 2001: “Un nuevo núcleo de arte rupestre postpaleolítico en Andalucía Oriental: el núcleo del río Guadalmena". Quaderns de Prehistoria i Arqueologia de Castelló 22: 281-320.

Utrilla, P. 2005: “Arte rupestre en Aragón. 100 años después de Calapatá". En M. Hernández y J. Soler (eds.): Arte rupestre en la España Mediterránea (Alicante, 2004): 341-378. Alicante.

Utrilla, P. y Blasco, F. 2000: "Dos asentamientos magdalenienses en Deza (Soria)". Boletín del Seminario de Estudios de Arte y Arqueología 66: 9-64.

Utrilla, P. y Calvo, M. ${ }^{a}$ J. 1999: "Cultura material y arte rupestre levantino: la aportación de los yacimientos aragoneses a la cuestión cronológica. Una revisión del tema en el año 2000". Bolskan 16: 39-70.

Utrilla, P. y Domingo, R. 2003: "El yacimiento magdaleniense de Peña del Diablo (Cetina, Zaragoza)". Saldvie 3: 15-45.

Utrilla, P. y Gimeno, J.M. a 1981: "Yacimientos líticos de superficie de la cuenca del Jalón". Papeles Bilbilitanos 3: 7-22.

Utrilla, P. y Martínez Bea, M. 2005-2006: "La captura del ciervo vivo en el arte prehistórico". Munibe 57 (3): 161-178.
Utrilla, P. y Martínez Bea, M. 2006: "Arte levantino y territorio en la España mediterránea". Clío Arqueológica 20: 17-52.

Utrilla, P. y Martínez Bea, M. 2007: "La figura humana en el arte levantino aragonés". Cuadernos de Arte Rupestre 4: 163-205.

Utrilla, P. y Villaverde, V. (eds.) 2004: Los grabados levantinos del Barranco Hondo (Castellote, Teruel). Monografías del Patrimonio Aragonés 1. Gobierno de Aragón. Zaragoza.

Utrilla, P.; González, P.; Ferrer, C. y Blasco, M. ${ }^{a}$ F. 1999: "La ocupación magdaleniense del valle del río Henar: los asentamientos de Cetina (Zaragoza) y Deza (Soria)". Geologia i Quaternari litoral. Memorial M.P. Fumanal. Universitat de València. Valencia: 283-296.

Vallespí, E. 1952: "Sobre las pinturas rupestres dels Secans (Mazaleón, Teruel)". Archivo Español de Arqueología XXV: 105-107.

Vilaseca, 1947: "Las pinturas rupestres de la Cueva del Polvorín (Pueblo de Benifazá, provincia de Castellón)". Informes y Memorias de la Comisión General de Excavaciones Arqueológicas 17: 7-42.

Villaverde, V. y Martínez Valle, R. 2002: “Consideraciones finales". En R. Martínez Valle y V. Villaverde (coords.): La Cova dels Cavalls en el Barranc de la Valltorta. Valencia: 191-202.

Villaverde, V.; Domingo, I. y López, E. 2002: "Las figuras levantinas del Abric I de La Sarga: Aproximación a su estilo y composición". En M.S. Hernández y J.M. Segura (coords.) 2002: La Sarga. Arte rupestre y territorio. Ayuntamiento de Alcoy y Caja de Ahorros del Mediterráneo. Alcoy: 101-126.

Villaverde, V.; Guillem, P. y Martínez Valle, R. 2006: "El horizonte gráfico Centelles y su posición en la secuencia del Arte Levantino del Maestrazgo". Zephyrus LIX: 181-198.

Viñas, R. 1982: La Valltorta. Arte rupestre del Levante español. Ediciones Castell. Barcelona.

Viñas, R.; Sarriá, E. y Alonso, A. 1983: La pintura rupestre en Catalunya. Altair. Barcelona. 